\title{
AN EXPLORATORY INVESTIGATION OF THE EFFECTS OF DRAGON BOATING ON THE PSYCHOSOCIAL WELL-BEING OF FEMALE CANCER SURVIVORS
}

\author{
A Thesis \\ presented to \\ the Faculty of California Polytechnic State University, \\ San Luis Obispo \\ In partial fulfillment \\ of the requirements for the degree of Master of Science in Kinesiology
}

by

Clara Therese Louise Vanherweg

August 2011 


\section{(C) 2011}

Clara Therese Louise Vanherweg

ALL RIGHTS RESERVED 


\section{COMMITTEE MEMBERSHIP}

TITLE:

AUTHOR:

DATE SUBMITTED:

COMMITTEE CHAIR:

COMMITTEE MEMBER: Camille P. O'Bryant, PhD

COMMITTEE MEMBER: Marilyn Tseng, PhD
An Exploratory Investigation of the Effects of Dragon Boating on the Psychosocial Well-Being of Female Cancer Survivors

Clara Therese Louise Vanherweg

August 2011

Suzanne Phelan, PhD 


\section{ABSTRACT}

An Exploratory Investigation of the Effects of Dragon Boating on the Psychosocial Well-

\section{Being of Female Cancer Survivors \\ Clara Therese Louise Vanherweg}

The purpose of this study was to prospectively examine the effects of dragon boat participation on the psychosocial well-being of female cancer survivors over time and compared with the population-based norms. Nine female cancer survivors belonging to the dragon boat team, SurvivOars, participated in the initial measurement process. The measurement packet was 21 page compilation of psychosocial questionnaires capturing demographics, quality of life, moods, depressive symptoms, perceived stress, self-esteem, self-efficacy, social support, physical activity levels, body image, and sedentary behaviors. After 8 weeks, 8 subjects completed the same follow-up questionnaire to assess changes in psychosocial variables over time. Scores were also compared to population-based norms from previous studies of similar groups of cancer survivors who did not participate in dragon boating. Results indicated no significant changes in psychosocial scores over the 8-week period. However, compared with population norms, significantly better psychosocial functioning was found in the dragon boating survivors compared with non-dragon boating survivors in quality of life , mood, self-esteem, perceived stress, body image, and depressive symptoms $(p<0.05)$. These findings suggest dragon boat participation among female cancer survivors may be beneficial to their quality of life and psychosocial well-being for life after disease. 


\section{AKNOWLEDGEMENTS}

Thank you from the bottom of my heart to my family, friends, colleagues and thesis committee who helped and supported me throughout this process. You all

know who you are. Without your prayers, support, and encouragement this would not have been possible. Thank you and God bless. 


\section{TABLE OF CONTENTS}

Page

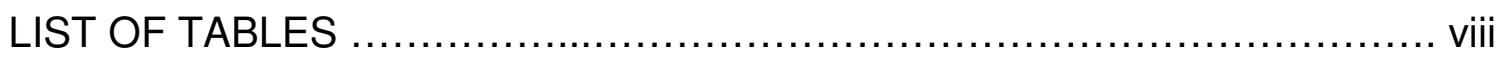

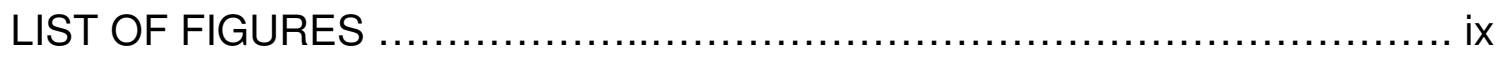

CHAPTER

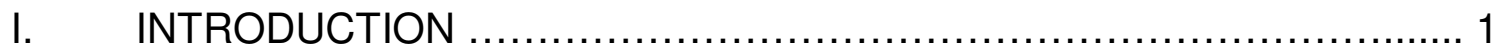

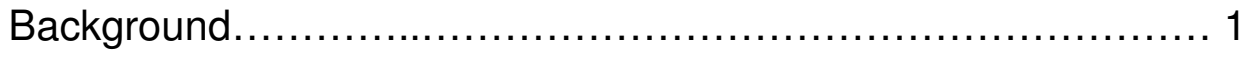

Statement of Problem ........................................... 2

Hypothesis ....................................................... 3

Assumptions ...................................................... 2

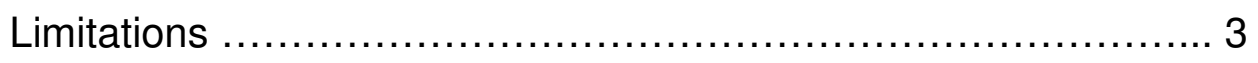

Measures to address limitations .................................. 4

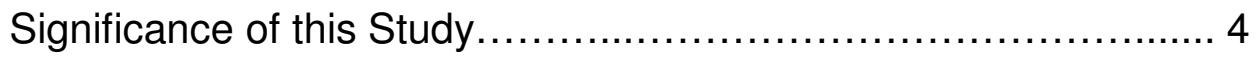

Definition of Terms …........................................... 5

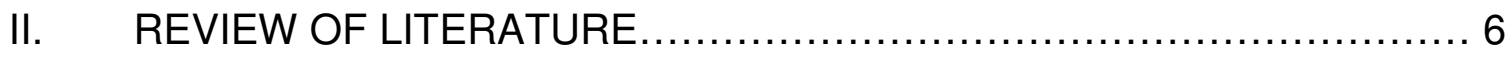

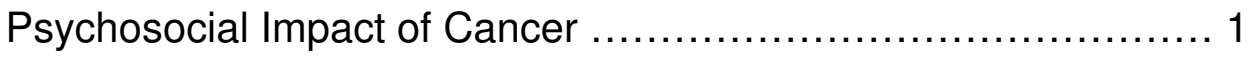

Exercise in Cancer Survivors ..................................... 2

Exercise and Quality of Life in Cancer Patients and Survivors ..... 3

Abreast in Boat- Development of Dragon Boating .................. 2

Theoretical Model ................................................. 3

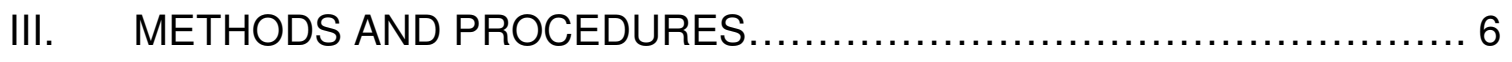

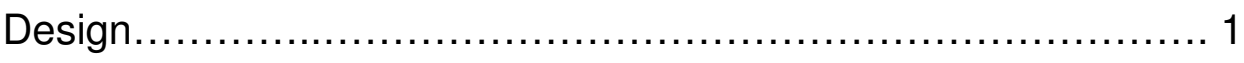

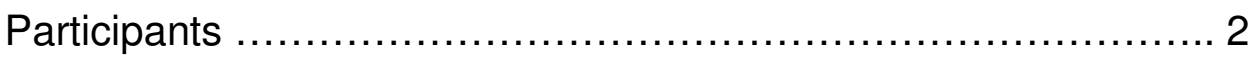


Recruitment...................................................... 3

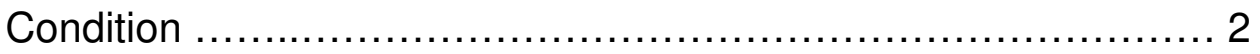

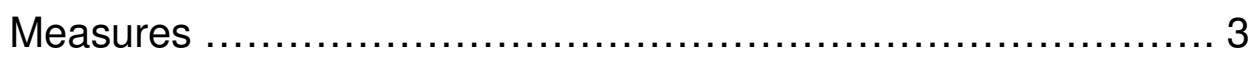

Power Calculation and Statistical Analysis ........................ 4

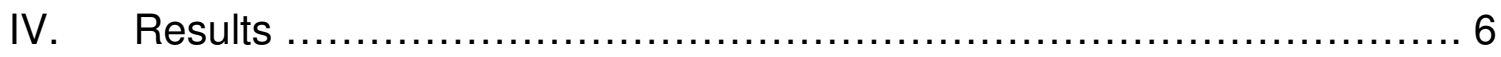

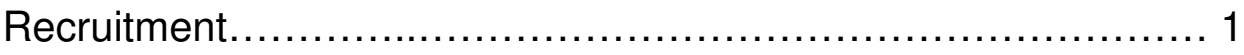

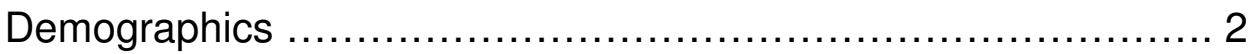

Eight Week Changes................................................ 3

Psychosocial Measurements .................................... 2

Correlations......................................................... 3

Measures to address limitations ................................. 4

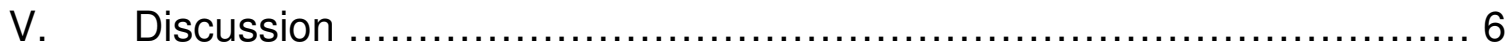

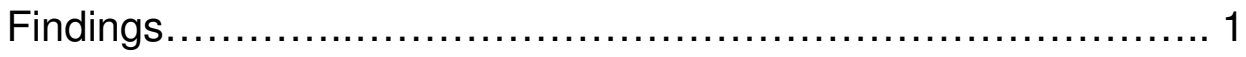

Limitations ......................................................... 2

Recommendations................................................ 3

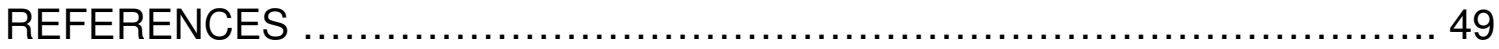




\section{LIST OF TABLES}

Table

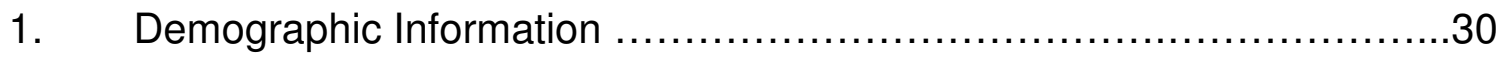

2. Mean changes from baseline to 8 weeks and t-test results................32

3. Comparison of dragon boaters with population norms …................34

4. Correlation between psychosocial variables and the number of prior races completed, years in dragon boat racing, current level of involvement, and

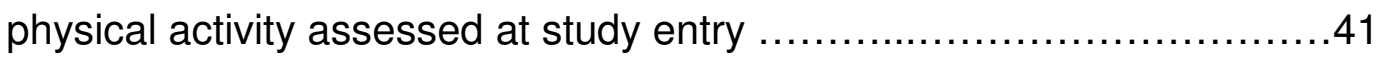




\section{LIST OF FIGURES}

Figure

Page

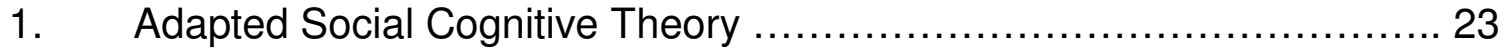




\section{Chapter 1}

Introduction

\section{Background}

According to the American Cancer Society, men and women respectively have $50 \%$ and $33 \%$ chances of developing cancer at some point during their lives. In 2009, an estimated 766,130 men and 713,220 women were reported to have cancer. Between 1996 and 2004,68\% of those with cancer survived at least 5 years after diagnosis (American Cancer Society, 2009). Survival depends greatly on the care, treatment, and support received during the course of illness. Traditionally, methods such as surgery, chemotherapy, and radiation have been used to treat cancer. In addition to these established treatments, exercise and physical activity along with social support are increasingly recognized as vital to success. Most doctors recommend exercise and physical activity to improve quality of life, increase energy levels, enhance functionality, and help alleviate some of the side effects of treatment (Durak, Harris, \& Ceriale, 2001).

Although research on the effects of physical activity in cancer survivors is limited in quantity, different modes and durations of exercise have been researched along with individual and group variations. Existing research suggests that exercise in a group setting with its accompanying social support is an effective method for promoting adherence and positive outcomes such as increased physical and psychological functioning (Courneya, Blanchart, \& Laing, 2001). 
One innovative approach to group exercise that has recently become popular and has been researched in cancer survivors is the ancient Chinese sport of dragon boat racing. Dr. Donald McKenzie is the leader in development and research of this practice. He was the first to hypothesize that upper body cardiovascular activity would be beneficial to breast cancer survivors who often develop lymphedema of the upper extremities as a result of lymph node removal during breast surgery (McKenzie, 1998). To date, dragon boat participation has been widely studied using qualitative methods and has been found to enhance wellbeing in cancer survivors. More recently, researchers have begun to use quantitative measurement tools to assess the relationship between exercise and quality of life in cancer patients, but research in this arena has been limited by use of only a limited number of cross-sectional measurements (Cadmus et al., 2009; Maryam, Fazollah, Eesa, Ebrahim, \& Abbas, 2010).

Statement of the Problem

Dragon boat racing is increasing in popularity and qualitative research shows it is a promising means of improving quality of life and psychosocial status in cancer survivors. However, there is a lack of prospective research that utilizes reliable, validated, quantitative measures of quality of life and psychosocial status. Thus, the purpose of this study was to conduct a preliminary examination of the prospective effects of dragon boat racing on the psychosocial status of cancer survivors. It was hypothesized that, relative to population norms, cancer survivors who participated in dragon boat training would have better self-esteem, 
body image, exercise self-efficacy, stress levels, sleep quality, mood, and overall quality of life.

Hypothesis

In this study, the researchers hypothesized that female cancer survivors who participate in dragon boating will experience increased quality of life, as measured by quantitative means on a variety of psychosocial variables over the course of dragon boat racing season and as compared with published population-based norms for cancer survivors.

\section{Assumptions}

In this study, the researchers assumed that survivor participants were honest when answering questionnaires and fully participating in dragon boat training sessions and races. The researchers assumed that published population norms reflected actual norms of the general population of cancer survivors. Limitations

The primary shortcomings of this preliminary study are its small sample size, lack of control group, and biases due to cancer type and years since treatment. Statistical findings from a sample size of nine are unlikely to generalize to the population at large. This study lacked an appropriate control group, limiting conclusions that can be drawn. Also, patients with different types of cancer, treatments, and time since diagnosis may respond differently to dragon boating. These were not exclusion criteria and differences on these variables could be responsible for more or less severe negative psychosocial 
outcomes. Measures were based on self-report, which could introduce problems of bias. Subjects were self-selected which could impose a bias.

Measures to address limitations

The delimitations of this study include the sample size, subjects'

characteristics, and questionnaires used. The small sample size limited power to detect effects in the current study but may provide preliminary estimates for a future, larger study. The subjects in the study had different types of cancer and different kinds of treatment, which were measured and accounted for in the statistical analyses. The questionnaires being used to assess psychosocial factors may not fully measure a participant's wellbeing, but they have been used in previous successful studies and are considered reliable and valid measures. Significance of this Study

This study aims to test the hypothesis that female cancer survivors who participate in dragon boating experience improvements in psychosocial health, including body image, exercise self-efficacy, self-esteem, mood, depressive symptoms, sleep quality, and social support over the 3-month course of the dragon boat racing season. Findings from this research will inform a future, larger study and inform potential ways to improve the quality of life for female cancer survivors as they readjust to life after disease. These findings may also inform clinicians, exercise specialists, and survivors on the possible options to enhance life after cancer. 


\section{Definition of Terms}

For the purpose of this study, Quality of Life refers to perceptions of overall wellbeing, physical health, mental health, and ability to function in daily activities (Cadmus et al., 2009).

Psychosocial factors include a person's general sense of self-worth, selfesteem, body image, self-efficacy, mood, and perceived social support.

Dragon Boating is training and racing on a team for the ancient Chinese rowing sport (United States Dragon Boat Federation, 2010). 


\section{Chapter 2}

Review of Literature

This section provides a review of the literature on the role of physical activity in improving psychosocial factors and quality of life in cancer survivors. The overview begins start with a review of the impact of cancer on psychosocial status and quality of life. Next, the role of exercise and its outcome on cancer patients and survivors will be reviewed. After that, studies on the effects of exercise on psychosocial status and quality of life in cancer patients and survivors will be presented. Finally, the practice of dragon boat racing among cancer survivors will be reviewed.

\section{Psychosocial impact of cancer}

Women who have had breast cancer experience decreased overall quality of life (Ganz, Kwan, \& Stanton, 2004). There are many psychosocial factors that play a role in quality of life, such as body image, self-esteem, sleep quality, depressive symptoms, and anxiety. These factors have been researched in numerous studies with particular attention to the time of life surrounding cancer treatment and survivorship.

The prevalence of psychiatric disorders in cancer patients is generally more prevalent than in other populations. Degrogatis and colleagues (1983) measured the incidence of psychiatric disorders in cancer patients. In a sample of 215 patients, 101 (47\%) were found to have a psychiatric disorder according to the DSM-III, which is higher than the national average, $26 \%$ of the US population (National Institute of Mental Health, 2005). Also, $85 \%$ of patients identified with a 
psychiatric condition had depression or anxiety as the central symptom (Derogatis et al., 1983). A later study measured anxiety, moods, and depression in 50 cancer patients and 50 other non-cancer medical patients. In this study, $44 \%$ of patients with cancer experienced psychiatric disorders following criteria from the DSM-IV. The most common disorder, depression, was seen in $28 \%$ of cancer patients. In this study, depressed cancer patients had significantly higher scores on the 'anger' subscale of the Profile Mood States (POMS) scale. Other findings included slight increases, but not significantly high scores, in the 'depression', 'fatigue', 'tension', and 'confusion' subscales of POMS (Hosaka \& Aoki, 1996). Another earlier study on distress and mood disturbances also supports the above findings with use of the Profile Moods States scale for measurement. Cancer patients reported higher degrees of distress and mood disturbances when compared with heart attack patients (McCorkle \& QuintBenoliel, 1983). These findings indicate that many cancer patients suffer from clinically significant depression, anxiety, and other psychological distress. Another facet that affects quality of life is body image (Hopwood \& Maguire, 1988). Because of drastic changes to the body that often take place due to breast cancer surgery, body image can be negatively altered. For example, a 1988 review on body image in cancer patients looked at the pioneer studies in this area of research dating back to 1978 . Findings indicated that $22 \%$ of sampled breast cancer patients reported moderately severe to severe problems dealing with loss of breasts due to cancer-related surgery. A study by Maguire in 1983 (cited by Hopwood \& Maguire) reported that 18\% of women 
were dissatisfied with their mastectomy scar and $24 \%$ were dissatisfied with the prosthesis, 12 to 18 months post-surgery. This study also noted that evaluating body image in cancer survivors is difficult because, "Patients are reluctant to reveal psychological problems for fear of being labeled as 'neurotic' or 'ungrateful'”' (Hopwood \& McGuire, 1988). Also, body image problems are important to find and treat because these can lead to other more complicated psychological problems such as affective disorder and sexual problems (Hopwood \& Maguire, 1988). The conclusion of this review was that cancer patients who fail to successfully adapt to their post-surgery body may very well be at risk for body image disorders and decreased quality of life (Hopwood \& Maguire, 1988).

A second body image study was a retrospective study of breast cancer patients who received either a partial mastectomy or breast reconstruction immediately after mastectomy. These two groups were compared on psychosocial adjustment, body image, and sexual function. The study did not find a significant difference in these factors between the groups. However, women who had received chemotherapy had poorer body image and more psychosocial distress. This sample population was atypical in that most of the participants had not received radiation therapy. Radiotherapy tends to be more damaging to local skin surfaces and causative of fibrosis to the area of treatment. These types of negative changes may be more likely to lead to poorer body image (Schover et al., 1995). Also related, cancer and its treatment can 
adversely affect self-esteem, but this area is not widely researched (Curbow \& Somerfield, 1991).

Sleep disturbances and co-morbid depressive symptoms are also more prevalent in cancer survivors and affect quality of life. For example, a study on the sleep-wake disturbances of long-term breast cancer survivors aimed to refine the body of the knowledge on severity, prevalence, and correlates of sleep-wake disturbances. A large sample size of 246 breast cancer survivors (BCS) and 246 control subjects (WWC) were assessed in a cross-sectional study. The BCS group was significantly higher on depressive symptoms as measured by the CES-D ( $P<0.05)$, indicating high incidence of depressive symptoms. Also, the BCS group had significantly more sleep disturbance (65\%) (Otte, Carpenter, Russell, Bigatti, \& Champion, 2010).

As illustrated by the previous studies, it is obvious that cancer can have a severe negative effect on many aspects of quality of life, including psychological functioning, depressive symptoms, body image, and sleep. Researchers have begun to study ways to improve quality of life and psychosocial factors in the lives of cancer patients and survivors. Exercise is widely researched and accepted as a means to improve quality of life in other populations (Farrel, Braun, \& Barlow, 2002). More recently, researchers have begun to investigate the role that exercise may play in cancer populations.

\section{Exercise in Cancer Survivors}

Exercise is a common practice for cancer patients and survivors and is encouraged by most physicians (Durak et al., 2001). One study examined a 
group of cancer patients and survivors engaging in physical activity. This study captured information from 50 participants in 16 different states. Also, a regional sample of 50 participants in a cancer wellness program in Sothern California was used. Both groups completed modified Rotterdam surveys that assessed cancer treatment, exercise habits, nutritional information, and quality of life (Durak et al., 2001). From this 6 year study, Durak and colleagues found that nationally, $87 \%$ and regionally, $98 \%$ of cancer patients' physicians were in favor of them exercising (2001). This study also found physical and emotional benefits from exercise among cancer survivors and cancer patients. Improved quality of life was reported by $13 \%(p<0.002)$, and both improved nausea $(p<0.003)$, and ability to cope with stress was reported by $27 \%(p<0.003)$. These findings suggest that in this physically active population, exercise appears to be safe and effective in reducing side effects and improving quality of life for cancer patients and survivors (Durak et al., 2001).

Other research has explored intention and motivation that drives exercise behavior in cancer survivors. In one study, 24 women who were cancer survivors and also engaged in physical activity were asked to complete a self-administered questionnaire on exercise intentions. The most significant contributor to intention to exercise and adherence was social support of physicians, spouses, and friends. A small convenience sample was used, but this study suggests that social support and encouragement may be a motivating force for women cancer survivors (Courneya et al., 2001). 
The effect of exercise on self-esteem has also been studied. For example, one study looked at the correlation between self-reported minutes of activity and self-esteem in cancer survivors. This study found that breast cancer survivors who exercised more often with higher exertion had higher self-esteem than women who exercised less often at lower intensity. Also, the women who exercised often and at higher levels also had a higher sense of physical competence and perception of physical ability. The results suggest intensity of exercise may play a role in positive benefits on self-esteem in cancer survivors, but the study was limited by use of self-reported data, self-selected sample, and cross-sectional method (Baldwin \& Courneya, 1997).

Preliminary research suggests that exercise appears to be safe after cancer and that it may improve self-esteem. Moreover, social support may play a role in promoting exercise in cancer survivors. However, research to date has not specifically addressed the effects of exercise on other psychosocial factors that are shown to be affected in cancer patients and survivors. More research is needed on the effects of exercise on sleep disturbances, body image, and depression.

\section{Exercise and Quality of Life in Cancer Patients and Survivors}

Several studies have found that exercise has many positive benefits for cancer survivors and, most notably, positive effects on quality of life (QoL). A meta-analysis and systematic review examined the effects of exercise on breast cancer patients and survivors. The 14 studies reviewed provided a large variety of exercise interventions including walking, jogging, resistance training, and Tai 
chi. The QoL measurement tool used in common by these studies was the Assessment of Cancer Therapy-General survey and the Functional Assessment of Cancer Therapy-Breast survey. The analysis concluded that exercise was a statistically significant factor on the improvement of QoL in breast cancer patients and survivors (effect size $=0.84$ ). The authors concluded that several types of exercise yielded the same results on quality of life (McNeely et al., 2006).

The following studies examined the same research area but were not included in the meta-analysis above. A large sample size of 374 breast cancer survivors was used to study the association between self-reported physical activity and quality of life. This study used the Short Form-36 physical and mental health measures via telephone interviews. An association was found between increase in self-reported exercise and higher score on the SF-36 physical $(p=0.005)$. A significant change was not seen in the mental health portion of the survey. These results support exercise as a means to increase overall well-being but not mental health in long-term breast cancer survivors (Kendall, MahueGiangreco, Carpenter, Ganz, \& Berstein, 2005).

Wiggins and Simonavice (2009) looked at changes in quality of life during a supervised exercise program involving bi-weekly cardiovascular and strength training sessions in cancer survivor. Measurements were obtained at baseline, 3 months, and 6 months. Significant improvements in quality of life were detected at both 3 and 6 months. However, the sample size was small, with only 8 female and 2 male subjects (Wiggins \& Simonavice, 2009). 
Finally, a recent study (Maryam, Fazollah, Eesa, Ebrahim, \& Abbas, 2010) in Iran studied the effect of a designed exercise program (cardiovascular warmup, strength training, and meditative cool-down) on QoL in women receiving treatment for breast cancer treatment. A quasi-experimental approach used 56 breast cancer patients. Control $(n=28)$ and exercise $(n=56)$ groups were formed from women receiving treatment at one center. The Quality of Life- Breast Cancer survey was used for measurement. At baseline, no QoL differences were detected. After a 9-week intervention, significant differences were detected in the exercise participants for physical $(p=0.004)$, emotional $(p=0.02)$, and spiritual $(p=0.045)$ health, as well as total QoL ( $p=0.003$ ) (Maryam et al., 2010).

Although the majority of studies have shown positive effects for physical activity on quality of life, there are some exceptions in the literature. In one welldesigned study, the effect of exercise on quality of life was studied on 2 populations: cancer patients and cancer survivors. A sample size of 50 participants was used for the cancer patient group; 25 subjects were randomized to an exercise program group and 25 in the usual care group. An additional 75 post-treatment survivors were randomized to an exercise intervention $(n=37)$ and a usual care group ( $n=38$ ). Several measures of QoL were used, including Fordyce Happiness Measure, Rosenburg Self-esteem Scale, and Centers for Disease Control- Depression Scale, Stait-Trait Anxiety Index. Participants also kept a 7-Day Physical Activity Log at baseline and 6 months. Anthropometric measurements included height, weight, and total body fat. In this randomized study, exercise was not associated with improved quality of life in any of the 
groups. However, exercise was associated with improved social-functioning among the cancer survivors who had low social-functioning at baseline $(p<0.05)$. This study used a randomized design, had good adherence, and a fairly large sample size. It remains unclear why finding diverge from other correlations studies (Cadmus et al., 2009).

Overall, most research suggests that exercise is a potentially effective means of improving quality of life for cancer patients and survivors. Few studies, however, have examined the effects of more cohesive, team oriented means of exercising. One means of exercise in the cancer community, especially among survivors, is the ancient Chinese sport of dragon boating.

\section{Abreast in a Boat- The Development of Dragon Boating}

A dragon boat holds up to 26 rowers who sit two abreast. The boat is 12 18 meters in length and races vary in length between 500 and 650 meters (Sabiston, McDonough, \& Crocker, 2007). In 1996, Donald McKenzie, PhD., established the first dragon boat team and named the project, "Abreast in Boat". His purpose was to enable breast cancer survivors to exercise and be a part of a project to help alleviate the "uncertainty and depression, often of considerable lengths, after active treatment ends". In the initial study, McKenzie and colleagues (1998) wanted to de-bunk the belief that exercise would increase the incidence and severity of breast surgery related lymphedema of the chest and upper extremities in survivors (McKenzie \& Kalda, 2003). The sport of dragon boating was chosen because it utilizes upper body cardiovascular exercise and incorporates a group setting (Mitchell, Yakiwchuk, Griffin, Gray, Fitch, 2007). The 
sample group was 24 female breast cancer survivors who volunteered to be a part of the spearhead project. They ranged in age from 31-65 years. The women were interviewed and reported feeling improved physical and mental health. Also, no cases of lymphedema occurred and improved shoulder range of motion was seen. These positive results could have been a product of self-selection to participate in the first female cancer survivors' dragon boat team (McKenzie, 1998). However, these findings helped to popularize dragon boating. An estimated 70 dragon boat teams exist across the United States (United States Dragon Boat Federation, 2010). These findings have also led to other research in this area.

Most subsequent research on dragon boating has used qualitative designs to examine the effects of DB on quality of life in the cancer population, and more specifically in breast cancer survivors. For example, the interview method was used by Mitchell and Nielsen (2001) who conducted a qualitative study to examine the overall dragon boat experience and effects on psychosocial factors. Subjects $(n=6)$ ranged in age from 43-75 years and had varying levels of dragon boat skill and length of participation. This study used a well structured interview guide to capture the main ideas (Mitchell \& Nielsen, 2001). A 1.5-2 hour interview was conducted and 9 categories were identified. These were as follows: Hopeful mission, common base, paddling and environment, camaraderie, regaining control, embracing life, facing disease, having fun, being focused, and moving on. The study underscored dragon boat participation as a positive experience in cancer survivors' lives. 
Another study by Mitchell and colleagues (2007) used the contructivist qualitative approach and uncovered both pre and post-season themes of dragon boat participation in 10 women. The 3 pre-season themes were body betrayed (by cancer), post-treatment needs, and hopes and expectations. The 5 postseason themes were self-awaking, common bond, regaining control, and uplifting transcendence. Although limited to only a Caucasian sample, these findings were consistent with Mitchell and colellagues' other study in suggesting that dragon boating is a positive means for breast cancer survivors to "reclaim and enhance life after treatment" (Mitchell et al., 2007).

A study of 20 participants conducted 45-60 minute interviews on a onetime basis to explore the social support, physical self-perception, and reasons why participants got involved in dragon boating. Five categories were indentified: persistent stressors, coping with stress, social support, positive psyche, growth, personal control, and self-perceptions. Consistency of interviewers was strength of the study, but the self-selected participants were a potential weakness (Sabiston et al., 2007). Overall, these findings suggest that DB involvement is motivated, in part, by psychological needs for breast cancer survivors.

The interpretative phenomenological perspective was used to qualitatively assess changes in body image and social support of dragon boat novice breast cancer survivors. Fourteen women were interviewed for 45-60 minutes on 2 occasions, beginning and end of dragon boat season. Improved perceptions of fitness, strength, physical appearance, and body shape were seen. There was a shift towards athletic identity and diverse social support. Dragon boat facilitated 
changes in psychosocial and social QoL. Body image correlations were consistent with previous physical activity studies. Social support and interactions were not exclusively positive (McDonough, Sabiston, \& Crocker, 2007).

A study by Parry (2006) aimed to capture a representation of the experiences lived by the breast cancer survivors involved in dragon boat. With twelve interviewed participants, the following themes surfaced: bond with other teammates, creating a new life, finding others in the same boat, solidarity, strength as a woman, dealing with diagnosis and treatment, back in control, life support, and the ability to face the unexpected (Parry, 2006). Thus, dragon boat training was seen as an effective way for breast cancer survivors to gain strength physically, emotionally, and mentally as part of a team with similar experiences.

Other qualitative studies have similarly reported (Unruh and Elvin, 2004) the use of dragon boat as a means to promote well-being, social support, and create awareness in the community and improved social, emotional, spiritual, and mental health of breast cancer survivors (Parry, 2009). A smaller portion of studies have used quantitative, survey methods to assess the effects of dragon boat on quality of life in cancer survivors. For example, one study (Culos-Reed, Shields, \& Brawley, 2001) measured physical activity levels (Godin Leisure Time Exercise Questionnaire), quality of life (SF-36), and cohesion (group cohesion questionnaire). These factors were assessed at the beginning and end of the dragon boat competitive season. Significant improvements in these measures pre and post dragon boat were found with the exception of changes in overall physical activity levels from early to late measurement. This study suggested 
potential benefits of dragon boat on quality of life and cohesion but contained few assessments overall and was a highly motivated self-selected sample population. Sample size started large $(n=109)$ but had low retention $(n=56)$ (Culos-Reed, Shields, \& Brawley, 2001).

Another study aimed to identify the stressors faced by breast cancer survivors in dragon boating. A large sample size $(n=470)$ assessed women from ages 20-80 years using a 28 item Stressors (compiled) and the Physical Self Description Questionnaire (global self-esteem and physical self-worth). This study found that although dragon boat participants experienced many sources of stress, they were able to adapt well to stress induced by exercise, and exercise was positively correlated with self-esteem. This one-time questionnaire measurement did not follow participants over time or capture at any particular time of season or training process (Hadd, Sabiston, McDonough, \& Crocker, 2009).

McKenzie and Kalda (2003) examined the effects of upper body cardiovascular and strength training on lymphedema secondary to breast cancer treatment, as well as the effect of strength training on quality of life. Although this study did not examine dragon boat in particular, dragon boat training is an upper body form of exercise and, thus, findings may be relevant to the current study. A sample size of 14 women was randomized into 2 conditions, resistance exercise and aerobic exercise of the upper body. Standardized measures of arm circumference and arm volume were taken to test for lymphedema. Also the short form-36 was used to assess quality of life at baseline and post-intervention. 
There were no changes in arm volume of circumference after exercise interventions were completed, suggesting no adverse effects on lymphedema. Moreover, a positive trend for improvements in psychological function $(P=.050)$, general health $(P=0.48)$, vitality $(P=.023)$ associated with both conditions. Anecdotally, all subjects reported increased "health of arms" due to exercise. This study had a small sample size and the intervention lasted only 8 weeks, but further suggests that upper body exercise appears safe in cancer survivors. Theoretical Model

In order to tie together the psychosocial and behavioral dimensions hypothesized to improve with dragon boat racing in this study, the Social Cognitive Theory has been adapted for use. Luszczynska and Schwarzer (2005) summarize the Bandura's Social Cognitive Theory as an individual's ability to change behavior based, in part, on belief in ability to change, or self-efficacy. Within the Social Cognitive Theory, individuals who have high levels of selfefficacy tend to lead more active, productive lifestyles and have better psychosocial profiles than individuals with lower self efficacy (Bandura, 2001; Maddux, 1995). As applied to dragon boating, belief in ability to engage in physical activity (e.g. dragon boating) is thought to influence cancer survivors' psychosocial profile, including mood, anxiety levels, depression, and self-esteem. Diagram 1 illustrates the interconnected nature of the Social Cognitive Theory and how these factors may interplay with the sport of dragon boating for cancer survivors. 
Figure 1 Adapted Social Cognitive Theory

\section{Personal Determinants:}

Self-efficacy

Mood

Depressive symptoms

Self-esteem

Body image
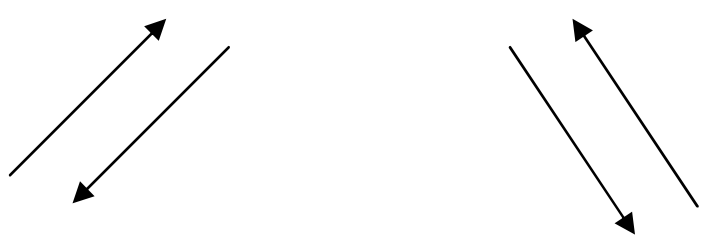

Behavioral Determinants:

Dragon boating

Other physical activity

Sedentary behaviors

Sleep
Environmental Determinants:

Social Support

Stress

\section{Summary}

In conclusion, cancer has a profound impact on reducing quality of life and psychosocial status in women. Exercise, dragon boating in particular, may counteract some of these negative effects. Preliminary research suggests that dragon boating provides an uplifting, safe, and potentially fruitful method to increase overall quality of life and psychosocial status. However, few studies have used quantitative methods with validated measures to study changes in quality of life and other psychosocial factors in dragon boat participants. If dragon boating improves quality of life and psychosocial status in cancer survivors, efforts could be made to disseminate this mode of physical activity more broadly to cancer survivors. 


\section{Chapter 3}

Methods and Procedure

\section{Design}

The purpose of this preliminary study is to prospectively explore the effects of dragon boat racing on the psychosocial status of cancer survivors over the course of 2 months of the racing season and relative to the population norms of cancer survivors who do not participate in dragon boating. Nine subjects were recruited between November 2010 and January, 2011 and assessed at the beginning of the dragon boat season in March 2011 and post-dragon boat racing in May 2011 (8 weeks later). The overall hypothesis was that dragon boat participation would lead to positive improvements in psychosocial measures and overall quality of life for female cancer survivors over time and compared to population norms.

\section{$\underline{\text { Participants }}$}

Inclusion/Exclusion Criteria: Subjects were 9 cancer survivors with a history of any malignant cancer type. Any cancer type was included as there is no evidence that type of cancer impacts quality for life or response to dragon boat racing, although type of cancer may differentially impact body image (Durak et al., 2001). Subjects were free of debilitating physiologic (e.g., cardiovascular or pulmonary disease, severe orthopedic conditions, fatigue related syndromes), or complicating psychological conditions (e.g., severe depression, schizophrenia, bipolar disorder). These criteria were selected to ensure that a pre-existing health condition did not skew potential results. Age parameters were between 35 and 
65 years to capture as many participants as possible while making sure age related issues did not dramatically affect results. Participants were screened for the above criteria by use of a screening form before being allowed to enroll in the study.

\section{$\underline{\text { Recruitment }}$}

Participants were recruited between November, 2010 and January, 2011. The group $(n=9)$ were recruited from dragon boat racing groups including "SurvivOars" in Morro Bay who met the inclusion criteria. Other teams approached for recruitment included Team Survivor in San Diego, Paddle Past Cancer in San Francisco, International Pink Sisters, and teams from Portland and New Jersey. For local teams, participants were recruited directly from the boat club meetings by the principal investigator (C.V.) and screened for eligibility. For out-of-the-area teams, coaches were contacted and asked to distribute an informational flyer to potentially eligible parties.

\section{$\underline{\text { Condition }}$}

Dragon Boat Condition: Subjects participated in standard training, as directed by the dragon boat coach. This involved weekly practices on 3 days and up to 3.5 hours of practice per week under direct supervision of the coach. Participants learned and practiced proper rowing technique and completed various drills to increase rowing capacity and speed. Racing and training were done on relatively calm bodies of water such as lakes and bays. The average length of a boat is 13.5 meters and holds from $20-26$ rowers. Races range in length from 200-2000 meters (Mitchell \& Nielsen, 2001). Participants were 
required to receive physicians' approval to exercise prior to participation in dragon boat racing.

Measures

Measures were collected at study entry and 8 weeks later and administered in person by the principal investigator (PI). The measurement packet included a demographic section, dragon boat participation and involvement rating scales, and 10 standardized measurement questionnaires. It was 21 pages and took approximately 30-40 minutes to complete. Participants completed the baseline questionnaires at their convenience at home. Follow-up measures were taken 8 weeks later, at which time the first dragon boat competition race was completed in May, 2011. Follow-up calls were made to participants to ensure completion of study measures. Upon completion of followup measures, all participants received an incentive t-shirt.

Demographics were measured at the beginning of the study using a standard questionnaire. Self-reported height and weight, type of cancer, type of treatment, current medications, age, race, income, employment, and exercise history were assessed. Self-reported weight was measured at follow-up, as well.

Perceived stress was assessed using the 4 questions of Perceived Stress Scale. This measure assesses stress over the past month, including feelings of loss of control of "the important things in life," as well as feelings of being overwhelmed. It has been shown to have adequate reliability $(r=0.84-0.86)$ and validity (Cohen \& Williamson, 1988). 
Social support for exercise was assessed using the Sallis Social Support for Exercise questionnaire, which contains 26 questions. This measure has two subscales measuring social support by family and social support by friends. This measure has been shown to be valid $(r=0.77-.88)$ and reliable $(r=0.82-0.88)$ (Rosenburg \& Morris, 1989).

The 20 question Centers for Disease Control- Depression scale (CES-D) was used to assess depressive symptom over the past month. This measure assesses feelings of worthlessness, depression, sadness, and loneliness but is not a diagnostic measure. This measure has been shown to be valid $(r=0.71)$ and reliable ( $r=0.46-0.68)$ (Radloff, 1977).

The Profile Mood States (POMS) was used to look at moods with 72 questions. This measure assesses both positive (e.g., good-natured) and negative (e.g., unhappy) aspects of mood at the present time. This measure has been tested to be valid ( $r=0.79)$ and reliable $(r=0.54-0.70)$ (McNair, Lorr, \& Droppleman, 1971).

To assess exercise self-efficacy the Sallis Self-Efficacy for Exercise Scale was used, which includes 12 questions. This measure captures how confident and able the person feels about their ability make time for and stick with exercise. This measure has been tested to be valid and reliable with a test-retest coefficient of $0.9(\mathrm{~N}=20)$ (Sallis, Pinski, Grossman, Patterson, \& Nader, 1988).

To assess sleep quality the General Sleep Disturbance Scale (14 questions and 2 subscales) was used. The subscales include sleep disturbance, 
hours of sleep at night, and hours of sleep during the day. This has been shown to be a valid and reliable measure $(r=0.74-0.81)$ (Gay, Kee, \& Lee, 1992).

Body image was evaluated using the Multidimensional Body-Self Relations Questionnaire (MBSRQ) which contains 7 questions. This assesses perceived attractiveness and comfort with looks and physique. This questionnaire has shown to be valid ( $r s>0.97)$ and reliable $(r=0.75-0.77)$ (Brown, Cash, \& Milkulka, 1990).

The Rosenburg Self-Esteem Scale was used to assess self- esteem with 10 questions. This measures self-worth, self-confidence, self-satisfaction, and self-respect. The validity $(r=0.77-.88)$ and reliability $(r=0.82-0.88)$ have been tested (Rosenburg \& Morris, 1989).

Quality of life was measured with the SF-36, which consists of 8 subscales and 36 questions. The eight subscales include: physical functioning, role limitations due to physical health, role limitations due to emotional problems, energy/fatigue, emotional well-being, social functioning, pain, and general health. The validity $(r=0.96)$ and reliability $(r=0.60-0.81)$ of this measure have been well established (Stewart, 1988).

Overall physical activity levels were captured with the Paffenbarger physical activity questionnaire, which includes 4 questions and 3 subscales. This measure has been shown to be valid and reliable $(r=0.34-0.72)$ (Paffenbarger, Wing, \& Hyde, 1978). The Paffenbarger provides estimates of overall caloric expenditure from exercise as well as calories expended in light, moderate, and high intensity physical activity. A TV viewing survey was used to uncover 
sedentary behavior with 3 question and 2 subscales, as used in previous research (Klem, Wing, \& McGuire, 1997).

Dragon boat participation was assessed by asking the participants to rate their current level of involvement and their current level of involvement compared to past seasons. For current involvement a 7 point scale will be used, $1=$ low involvement, 5 moderate involvement, high involvement. For current compared to past involvement a 7 point scale will be use, $1=$ not involved at all, $5=$ same involvement as past, $7=$ much more involved.

Power Calculation and Statistical Analysis

Power to detect a difference between dragon boat racers and non-racing population norms was estimated based on a study by Maryam and colleagues that looked at the effects of exercise on quality of life in female breast cancer patients receiving chemotherapy. Based on these data, expected changes in quality of life in the exercising vs. control conditions were $4.4 \pm(10.68)$ vs. -11.08 $\pm(14.83)$, respectively. With 56 subjects, assuming a type-I error rate of 0.05 , the power was $98 \%$ for testing the null hypothesis of no effect for exercise on quality of life. 
The dragon boat baseline and 8 week questionnaires were compared using dependent sample t-tests. Dragon boat baseline results were compared with published population norms using one-sample t-tests. Pearson's correlations were used to find correlations between each of the measurement questionnaires and perceived participation, years in dragon boating, physical activity levels, and number of races completed. 


\section{Chapter 4}

\section{Results}

\section{$\underline{\text { Recruitment }}$}

Thirty-one members of the dragon boat team in Morro Bay, SurvivOars, were approached to participate in the study. Of the $31,22(70.9 \%)$ declined to participate. Nine members were screened, determined eligible, enrolled, and signed consent forms. During the course of the study, one member developed a chronic back problem and did not complete the final assessment. All of the others, $(8 / 9,88 \%)$, completed the full assessment process at study entry and after 2 months. Repeated efforts to recruit dragon boat members from out of the area via phone calls to coaches proved unsuccessful.

\section{Demographics}

Participants' demographic information, cancer history, and history of dragon boat participation are summarized in Table 1. The mean age of the women was $55.8 \pm 5.7$ years, with a range of 46 to 64 years. On average, participants were overweight $\left(B M I=25.26 \pm 2.7 \mathrm{~kg} / \mathrm{m}^{2}\right)$. The range for BMI was 20 to 28.6 . Four participants (50\%) were employed, 3 (37.5\%) were retired, and 1 (12.5\%) was unemployed. Three (38\%) had an income greater than or equal to $\$ 50,000$ (Table 1).

The average years since completion of cancer treatment was $6.5 \pm 8.0$, ranging from 2 to 21 years; $87.5 \%(n=7)$ of the subjects were diagnosed and treated for breast cancer; 1 (12.5\%) reported cancer other than breast cancer. 
For treatment types $57.14 \%$ had undergone surgery, $87.7 \%$ had chemotherapy, $25 \%$ had radiation, and $12.5 \%$ had other treatment.

The average years of dragon boat participation was $2.5 \pm 1.0$, ranging from 2 to 4 years. Participants had competed in an average of $5.0 \pm 4.5$ races prior to current race, with a range of 1 to 12 races. Subjects were asked to rate their current level of involvement in dragon boat racing compared to previous seasons on 7 point scale where $1=$ not involved at all, $5=$ =about same involvement, and 7=much more involved. The participants' ratings indicated that their involvement in the current season was, on average, the same as it had been in past dragon boating seasons (average of $5.5 \pm 1.4$ ). 
Table 1 Demographic Information $\mathrm{N}=9$

Age (years)

BMI (kg/m2)

\section{Employment}

\% Employed

$\%$ Unemployed

$\%$ retired

Personal Income

$>\$ 50,000 /$ year

Type of Cancer

\% Breast Cancer

$\%$ Other Cancer

\section{Treatment}

$\%$ Surgery

\%Chemo

\%Radiation 25

$\%$ Other

Years since cancer treatment completion

$6.5 \pm 8.0$

Prior Dragon Boat Participation

\# Years

$2.5 \pm 1.0$

\# of races

$5 \pm 4.5$

Current level of involvement compared to prior*

\section{Eight week changes}

Changes in measurements over the 2 month study period are reported in Table 2. On most measures, scores declined slightly, suggesting a general decrease in overall psychosocial functioning from before to shortly after the 
dragon boat race. However, as summarized in Table 2, no statistically significant changes were observed. 
Table 2 Mean changes from baseline to 8 weeks and t-test results $N=8$

\begin{tabular}{|c|c|c|c|}
\hline SF- 36 (Quality of Life) & Mean change & T-values & $p$-values \\
\hline Physical functioning & $.63 \pm 3.20$ & -0.23 & 0.823 \\
\hline Role limitations due to physical health & $-12.5 \pm 23.15$ & 0.97 & 0.362 \\
\hline Role limitations due to emotional & $-2.09 \pm 5.90$ & 0.11 & 0.915 \\
\hline Energy/fatigue & $-3.63 \pm 7.89$ & 0.65 & 0.529 \\
\hline Emotional Well-being & $0.75 \pm 5.65$ & 0.10 & 0.925 \\
\hline Social Functioning & $-3.13 \pm 20.86$ & 0.40 & 0.695 \\
\hline Pain & $-2.50 \pm 19.50$ & 0.19 & 0.854 \\
\hline General Health & $-7.19 \pm 19.33$ & 1.35 & 0.205 \\
\hline Profile Mood States & $4.63 \pm 25.85$ & -0.59 & 0.573 \\
\hline Rosenburg Self-Esteem & $-0.75 \pm 3,92$ & 0.39 & 0.705 \\
\hline \multicolumn{4}{|l|}{ Sallis Social Support } \\
\hline Family & $0.63 \pm 9.05$ & -0.06 & 0.956 \\
\hline Friends & $-3.00 \pm 14.41$ & 0.33 & 0.750 \\
\hline Perceived Stress & $-0.13 \pm 3.68$ & 1.57 & 0.141 \\
\hline $\begin{array}{l}\text { Multidimensional body self-relations } \\
\text { questionnaire }\end{array}$ & $0.17 \pm 0.37$ & 0.14 & 0.893 \\
\hline CES-D & $3.06 \pm 8.92$ & -0.74 & 0.478 \\
\hline \multicolumn{4}{|l|}{ Sallis Exercise Self-Efficacy } \\
\hline Sticking with it & $-0.09 \pm 1.52$ & 0.97 & 0.356 \\
\hline Making time & $-0.34 \pm 1.05$ & -0.28 & 0.786 \\
\hline Paffenbarger & $\begin{array}{r}-1312.25 \pm \\
3421.24\end{array}$ & 0.78 & 0.453 \\
\hline $\begin{array}{l}\text { General Sleep Disturbance Scale } \\
\text { Sedentary Behaviors }\end{array}$ & $0.58 \pm 0.29$ & -0.37 & 0.720 \\
\hline TV watching & $0.88 \pm 12.16$ & -0.19 & 0.853 \\
\hline Sitting & $0.88 \pm 7.53$ & -0.18 & 0.860 \\
\hline
\end{tabular}


Of note, depressive symptoms increased markedly in two subjects as evidenced by increases in CES-D (from 13 to 25.5 in one and from 5 to 24 in the other). Evidence of increased negative mood was seen in only one of these subject's POMS scores as well (negative moods increasing by 64 points). One participant reported that her increased negative mood was due to heightened stress related to caretaking of a family member. The increase for the other participant was not explained, as she did not respond to a follow-up call after completion of the questionnaire. Of note, depressive symptoms score improved drastically for one participant on the CES-D, (from 14 to 4) and remained generally unchanged for the remaining 5 participants.

Psychosocial measurements: Dragon boat racing versus population norms

The questionnaires in the measurement packet were intended to capture quality of life and psychosocial well-being. Scores on questionnaires of participants in the current study were compared with breast cancer survivor population norms. 
Table 3 Comparison of dragon boaters with population norms

Dragon boat

\section{Dragon Boat Participation}

Perceived level of involvement *

SF-36

Physical Functioning

Role Limitations due to physical health

Role Limitations due to emotional problems

Energy/Fatigue

Emotional Well-Being

Social Functioning

Pain

General Health

POMS

Rosenburg Self-Esteem

\section{Sallis Social Support}

Family

Friends

Perceived Stress

Multidimensional Body Self-Relations

Questionnaire

Depressive symptoms

\section{Exercise Self-Efficacy}

Sticking with exercise

Making time to Exercise

Paffenbargers (kcal/week)

General Sleep Disturbance Scale

Sedentary Behavior

Hours viewing TV per week

Hours spent sitting per week
$5.5 \pm 1.1$ 
Quality of life was measured using the SF-36 questionnaire with its eight subscales. Scores from dragon boat subjects were compared with those in a previous, large scale $(\mathrm{N}=1957)$ study of breast cancer survivors recruited from tumor registry listings, hospital and clinic records, and the offices of oncologists and surgeons who were 1-5 years post treatment without physical or psychiatric conditions and demographically similar to those in the current study (Bower et al., 2000). Overall, dragon boat subjects scored higher in all eight subscales relative to published population (Table 3). In the current study, average values for the physical functioning subscale was reported as $95 \pm 5.34$ ( Range $=90-100$ ), indicating a high level of quality of life, which was significantly higher $(p<0.001)$ than the norm of $80.65 \pm 21.32$ reported in the study by Bower et al. Overall, dragon boat subjects scored higher in all eight subscales relative to the published population norms reported by Bower et al.(2000). Role limitations due to physical health were reported at an average of $93.75 \pm 11.57$ (Range $=75$-100 ) for dragon boaters while the population norms averaged significantly lower at $75.79 \pm 35.06$ $(p=0.003)$. Role limitations due to emotional problems for the subjects were 81.25 $\pm 37.2,($ Range $=0-100) ;$ population norms did not significantly $(p=0.915)$ differ at $76.7 \pm 34.6$. Energy and fatigue averages were $77.5 \pm 10.69$, (Range $=$ 65-100) which were significantly lower than population norm at $59.63 \pm 21.4$ $(p=0.002)$. Emotional well-being was $86 \pm 9.06$, (Range $=72-100)$, for dragon boaters and significantly lower in the population norms of $59.63 \pm 21.4(p=0.010)$. Social functioning was measured at an average of $95.3 \pm 13.26$, (Range $=62.5$ 100) which did not significantly differ from population norms at $85.4 \pm 20.8$ (Bower 
et al., 2000). Pain was reported at $76.88 \pm 23.44$, (Range $=40-100)$ which did not significantly differ from population norms at $78.72 \pm 20.98$ (Bower et al., 2000). General health was rated by the subjects at $88.13 \pm 13.08$, (Range $=65-100)$ with population norms significantly lower at $72.45 \pm 20.2$ ( $p=0.012$ ) (Bower et al., 2000).

Mood was measured using the Profile Mood States questionnaire; on this questionnaire, lower scores indicate more positive moods. Scores were compared the population norms published in a study of 218 breast cancer survivors who were an average of 5.5 years post treatment and otherwise similar to women in the current study, being mostly white, married, and earning salaries greater than $\$ 45,000$, with an average age of 56.5 years and being 16 to 36 months post-treatment (Polinsky, 1994). At baseline, POMS scores of participants in the current study indicated fairly positive moods with an average of $-14.25 \pm 8.26$, (Range $=-25-2)$ which was significantly higher $(p=0.003)$ than scores of $9.14 \pm 27.14$ reported by Polinsky (1994).

Self-esteem was measured using Rosenburg's self-esteem questionnaire. Scores were compared to population norms published in a study of 60 breast cancer survivors who were 35 years of age or older, disease-free, first time breast cancer survivors, ranging from 2 months to 5 years post-treatment (Carpenter, Brockopp, \& Andrykowski, 1999). Similar to the current study, the average age of the women in this comparative sample was 54 years and most of the women were white and married. Dragon boat participants in the current 
study reported a significantly higher average score of $27.13 \pm 3.94$, (Range $=20$ $30)$ versus $20.8(p=0.003)$, indicating better self esteem.

Sallis Social Support questionnaire is divided into two subscales, support from family and support from friends, with higher scores indicating more social support. Findings from the current study were compared to those published from a study of 34 breast cancer survivors (Damush, Perkins, \& Miller, 2005) who had completed treatment in the previous 5 years, were $91 \%$ Caucasian, and middleupper class income bracket (Damush, Perkins, \& Miller, 2005). The subjects were recruited from 2 university affiliated urban cancer centers. Overall, scores in the racers in current study were higher than published norms but not statistically different (Table 3).

Stress was measured in this study using the Perceived Stress Scale, higher scores indicate more stress. Scores from the current study were compared with a population sample of 84 breast cancer survivors recruited from a cancer research center in Tampa, Florida from 2006 to 2007, who were at least 18 months post cancer treatment (Lengacher et al., 2009) and relatively healthy, although some particpants had hypertension (30\%), diabetes (10\%), and were taking anti-depressant medication (25\%) (Lengacher et al., 2009). The average scores for dragon boaters in the current study ( $4.25 \pm 2.92$ vs. $14.5 ; p=0.0001)$ were significantly lower than a study of these 84 survivors.

Body image was assessed in this study using the Multidimensional body elf-relations questionnaire. Scores were compared with subjects in a study of 252 breast and endometrial cancer survivors who ranged in age from 55 to 65 years 
old, were recruited from 2003 to 2004 , and ranged from 2.9 to 4.5 years posttreatment. This population was $93 \%$ white while $78 \%$ were married (Kornblith et al., 2007). A higher score on this questionnaire indicates better body image. The average scores for the dragon boaters in the current study was $3.03 \pm 0.4$, (Range $=2.29-3.57)$, which was significantly higher than the non-dragon boating survivors (2.58 $\pm 0.81 ; p=0.018)$ (Kornblith et al., 2007).

Depressive symptoms were measured using the CES-D. Higher scores indicate more depressive symptoms. The dragon boat average was $4.38 \pm 5.92$, (Range $=0-14)$, which was higher $(11.03 \pm 9.78 ; p=0.016)$ than those reported in a study on fatigue in 863 breast cancer survivors (Bower et al. 2000). (The subjects from this study were previously described in the section on the SF-36.)

Exercise self-efficacy was measured using the Sallis Exercise SelfEfficacy scale which breaks into two subscales, sticking with exercise and making time for exercise. As little data were available on exercise self-efficacy in survivors, we compared our sample with physically active women (non breast cancer survivors) The averages for sticking with exercise and making time for exercise did not significantly differ from physically active women (non-breast cancer survivors), who were skilled labor employees (Ebel, Aldana, Bloswick, \& Lyon, 2003)..

Paffenbarger's Physical Activity questionnaire was used to assess weekly caloric expenditure (Paffenbarger et al., 1978). Scores were compared with nondragon boating cancer survivors. Dragon boaters reported an average of 5153 kcals/week, $($ Range $=1652-14,730)$, which did not significantly differ from the 
$2,500 \mathrm{kcals} /$ week reported in a study of 86 breast cancer survivors who did not participate in dragon boating (Pinto et al., 2002). The subjects in the study by Pinto and colleagues were recruited from 1997 to 1998 by newspaper advertisement and flyer solicitation near the Miriam Hospital in Providence, RI. These women had been diagnosed with breast cancer between 4 and 288 months previous to the study, were an average age of these women was 54.8 years, $97 \%$ were white, $63 \%$ were married, and $40 \%$ reported annual incomes of $\$ 50,000$ or higher (Pinto et al., 2002).

Sleep quality and disturbances were measured using the General Sleep Disturbance Scale (GSDS). Dragon boaters had an average score of $3.21 \pm 1.21$, (Range $=2.10-5.44)$, indicating relatively low sleep disturbance. When compared with a population of cancer patients undergoing treatment (GSDS=5.60 \pm 2.60 ), dragon boat participants had significantly lower sleep disturbance $(p=0.001)$.

Sedentary behaviors were reported by hours spent weekly watching TV and hours spent weekly sitting. On average the women in this study watched TV for $12.5 \pm 9.53$, (Range $=0-25$ ) hours per week at baseline. On average the women spent $8.75 \pm 9.9$ hours sitting, (Range $=0-30)$. These numbers were totaled to estimate hours of sedentary behavior per week for dragon boat participants $21.25 \pm 9.70$ hours/week. According to a study by Matthews and colleagues (2008), the average American spends $53.3 \pm 0.70$ hours per week in sedentary behaviors. This is significantly more sedentary time than the dragon boat group $(\mathrm{p}=0.001)$. 


\section{Correlations}

As history of dragon boat racing may relate to psychosocial status, the researchers explored these associations (Table 4). Participants who reported a more extensive history of dragon boat racing reported lower emotional well-being $(R=-0.72, p=0.04)$ and lower self-esteem $(R=-0.97, p=0.00)$. However, those women who had been participating in dragon boating for longer $(R=0.67, p=0.07)$ and who reported a history of more dragon boat races $(\mathrm{R}=0.80, \mathrm{p}=0.02)$ reported greater increases in self-esteem over the eight week study.

Higher reported level of involvement in the current dragon boat racing was related to better current psychosocial health $(R=0.92, p=0.001)$, fewer role limitation due to physical health $(R=0.68, p=0.06)$, less TV viewing $(R=-0.77$, $p=0.03)$ but also less exercise self efficacy $(R=-0.95, p=0.001)$. As involvement increased over the 8 week study, depressive symptoms improved $(R=-0.67$, $p=0.07)$ and role limitations due to physical health lessened $(R=0.68, p=0.06)$ and exercise self efficacy increased $(R=0.87, p=0.005)$.

As higher physical activity may also relate to improved psychosocial status, the researchers also explored associations between physical activity and the psychosocial measures. Subjects with higher levels of physical activity at entry reported less bodily pain $(R=0.66, p=0.08)$ and more family support for exercise $(R=0.73, p=0.04)$. No other significant correlations were observed. 
Table 4 Correlation between psychosocial variables and the number of prior races completed, years in dragon boat racing, current level of involvement, and physical activity assessed at study entry.

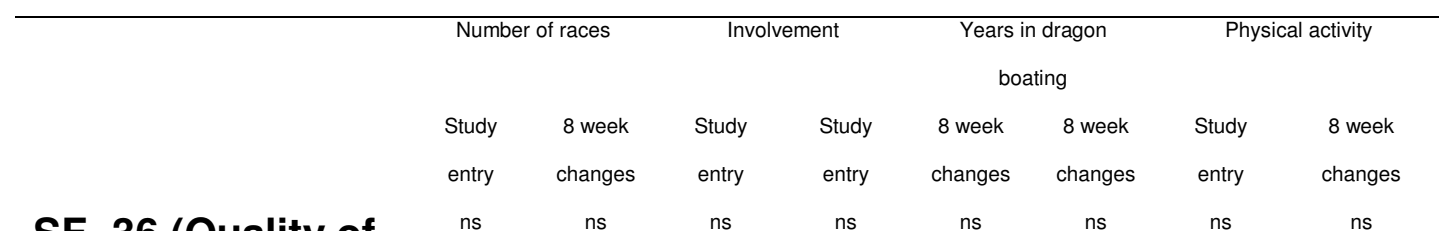

\section{Life)}

Role limitations due to physical health

Role limitations due to emotional problems

Emotional Well-being

Pain

General Health

\begin{tabular}{|c|c|c|c|c|c|c|c|}
\hline ns & ns & $\begin{array}{c}R=0.68 \\
P=0.06\end{array}$ & ns & ns & $\begin{array}{l}R=0.68 \\
P=0.06\end{array}$ & ns & ns \\
\hline ns & ns & $\begin{array}{c}R=0.87 \\
P=0.005\end{array}$ & ns & ns & ns & ns & ns \\
\hline ns & ns & ns & ns & ns & ns & $\begin{array}{l}R=-0.72 \\
P=0.04\end{array}$ & $\mathrm{~ns}$ \\
\hline ns & ns & ns & $\begin{array}{l}R=0.66 \\
P=0.08\end{array}$ & ns & ns & ns & ns \\
\hline \multirow[t]{2}{*}{ ns } & ns & ns & ns & ns & $R=0.92$ & ns & ns \\
\hline & & & & & $P=0.001$ & & \\
\hline
\end{tabular}

Rosenburg Self-

\section{Esteem}

Sallis Social

\section{Support}

Family

\section{CES-D}

Sallis Exercise

$R=0.80$
$P=0.02$

ns P.

ns

$\mathrm{R}=-0.97 \quad \mathrm{R}=0.67$

$\mathrm{P}=0.00 \quad \mathrm{P}=0.07$

\section{Self-Efficacy}

Sticking with it

$$
\text { ns }
$$$$
\text { ns }
$$

ns

ns

\section{Paffenbargers}

Sedentary

ns ns ns

ns

$$
\begin{aligned}
& R=0.73 \\
& P=0.04
\end{aligned}
$$

ns

ns ns

ns
$R=-0.67$

$\mathrm{P}=0.07$

\section{Behaviors}

TV watching

Sitting ns

ns ns ns

ns

ns ns

ns ns
$R=-0.77$
$P=0.03$ $\mathrm{P}=0.03$
$\mathrm{~ns}$ ns
ns ns 


\section{Chapter 5}

Discussion

Previous research has suggested that dragon boat racing is an effective way to improve psychosocial functioning and overall quality of life in breast cancer survivors (Cadmus et al., 2009; Culos-Reed, Shields, \& Brawley, 2001; Mitchell \& Nielsen, 2001; Wiggins \& Simonavice, 2009). However, existing research has been qualitative in nature and use of prospective methods and quantitative measures to assess quality of life and psychosocial status have been lacking. The purpose of this study was to gather preliminary data researching female breast cancer survivors who participate in dragon boating using validated, quantitative measurements on an array of quality of life and psychosocial components. The research hypothesis was that breast cancer survivors who participated in dragon boating would experience increases in quality of life and psychosocial measures over time. Also, dragon boaters would exhibit better quality of life and psychosocial status when compared to populations of cancer survivors who do not participate in dragon boating.

\section{Findings}

Contrary to our hypothesis, in this exploratory study the researchers saw no significant changes or, if anything, a slight decline in quality of life and psychosocial functioning in the dragon boat group over an 8 week period. This contrasts other research from qualitative studies, (Kendall et al., 2005; McNeely et al., 2006; Wiggins \& Simonavice, 2009), and one quantitative study (Maryam et al., 2010) showing significant increases in overall quality of life using a 
quantitative measure for breast cancer patients who had recently begun an exercise intervention. The reason for the discrepant findings is unclear. It is possible that our small sample size prevented detection of a significant change. Also, the 8 week time period was short and it is possible that benefits would be more apparent over a longer time frame (i.e., prior to training then 1 month after race completion). Also, our sample was seasoned dragon boat racers who may have "maximized" their improvements associated with dragon boat racing. Findings from novices could differ. Future research with more frequent assessments and long-term follow-up is needed.

Interestingly, the dragon boat group overall had better psychosocial and quality of life scores compared to published populations norms of other breast cancer survivors similar to the current study (an average of 5 years after diagnosis). Most pronounced were better quality of life scores among dragon boat racers in domains relating to physical functioning, energy/fatigue, emotional well-being, social functioning, and general health. Also the dragon boat group reported better mood, self-esteem, stress, body image, and depressive symptoms than population norms. The reasons for apparent better psychosocial functioning and quality of life in dragon boat racers in the current study are unclear but findings are consistent with other qualitative (Kendall et al., 2005; McKenzie, 1998; McNeely et al., 2006; Wiggins \& Simonavice, 2009) and quantitative (Culos-Reed, Shields, \& Brawley, 2001; Hadd et al., 2010) studies. Baldwin and Courneya (1997) found that cancer survivors who participated in more strenuous physical activity had better self-esteem than those who did less 
intense exercise. Dragon boat racing is considered a strenuous activity (McKenzie \& Kalda, 2003). Thus, this might explain the better psychosocial health. Courneya and colleagues (2001) found social support to be a helpful component to successfully improve psychological status of exercising cancer survivors. Thus, it is also possible that the team building and group cohesion experienced by these women may also play a part in their enhanced psychosocial functioning and quality of life. However, these were not measured in the current study. Future prospective research with a larger sample size and a control group is needed.

It is possible that women who seek out dragon boat racing have better psychosocial health than non-racers; however, surprisingly, we found that women with more years experience in dragon boat racing had worse psychosocial functioning than less experienced counterparts at study entry. Nonetheless, these women experienced greater improvements in functioning over the 8 weeks of dragon boat racing. Perhaps women who continue to participate in dragon boat racing do so, in part, because they have worse psychosocial status and seek out the needed support of a dragon boat team.

Also of interest, women who reported greater perceived involvement in the dragon boat season reported higher psychosocial functioning and quality of life at entry and greater increases in psychosocial functioning over 8 weeks. Other research on motivation has shown that greater perceived motivation during an activity program is correlated with increased satisfaction, competence, selfesteem, and bodily functioning (Frederick \& Ryan, 1993). Future research should 
examine whether motivation is related to perceived involvement and whether increasing perceived involvement improves psychosocial outcomes in dragon boat racers.

Also of note is the variability in responses amongst the individual women. For example, the depressive symptom scores of the CES-D increased for two of the eight women and decreased markedly for one other dragon boat participant. Unmeasured life events or other factors related (fatigue) or unrelated (underlying disease) to dragon boat racing may explain these differences and merit further investigation in a future study with a larger sample size.

\section{Limitations}

This study was designed to be exploratory in nature and, as such, has several weaknesses. As noted earlier, one limitation of this study was its small sample size $(\mathrm{N}=8)$. The sample in the study was self-selected and it is possible that this group of dragon boating cancer survivors was very different from the general population of dragon boat racers. Despite extensive recruitment efforts, cancer survivors in dragon boat racing were reluctant to participate in the study. The 8 women who joined the study came from the local dragon boat team. For this small sample however, the drop out rate was very low, as only 1 out of 9 women did not complete the assessment process. The researcher was able to meet with participants in person, increasing responsiveness to complete the study. Perhaps recruitment of other dragon boat teams would be successful with face-face recruitment and testing. 
The published population norms were comparable to the current study but not recruited at the same time or in the sample place. The study was originally designed to recruit cancer survivors without a history of dragon boat racing as a control group. Extensive efforts, including attendance at support group meetings, yielded no participants for a control group. Future research should develop effective recruitment strategies for recruiting both controls and other dragon boat racers.

Future research is also needed to compare dragon boat racing with other sports and athletic activities. The gravitational hypothesis suggests that there is a difference in the psychological profile of individuals who are drawn to sports, athletes, versus non-athletes (McKelvie, Lemieux, \& Stout, 2003). Perhaps it is the team and sport aspects of this dragon boating team that allows them to have better psychosocial functioning than their non-dragon boating counter parts.

The study used quantitative measure with adequate reliability and validity demonstrated in prior research. However, questionnaire measures are based on self report and could be prone to bias. Future research with larger sample sizes should consider a combined approach of quantitative and qualitative measures (even in a subset of women) to improve validity of the study's findings.

The study used an 8 week time frame that perhaps did not correctly capture psychosocial changes. It is possible that the measures used in this study were not sensitive enough to detect changes in the 8 week time frame or that some of the constructs measured (e.g., self esteem, self-efficacy) tend not to 
change over such a short time frame. Future research should be conducted to measure participants at longer time intervals to better track changes over time. Participants were mostly white females, so findings may not generalize to other populations. Also, the study did not include novices to dragon boating. It is possible that novices would experience greater improvements in psychosocial status than seasoned racers. Future research is needed to examine the impact of dragon boat racing in more diverse samples.

\section{Recommendations}

For future studies in this arena, extensive recruitment should be a major goal. Dragon boat novices should be targeted as the main research subjects to identify the time of change that takes place upon beginning physical exercise, particularly dragon boat participation. Also, a control group of non-dragon boating cancer survivors should be successfully recruited to distinguish if there are differences between dragon boating and non-dragon boating populations of cancer survivors. Different dragon boating teams should be compared to each other on each of the psychosocial variables. 


\section{References:}

American Cancer Society (2009). Statistics. http://www.cancer.org. Retrieved from the world wide web 20 March 2010.

Anderson, K.; Getto, C.; Mendoza, T.; Palmer, S.; Wang, X.; Reyes-Gibby, C.; Cleeland, C. (2003). Fatigue and sleep disturbance in patients with cancer, patients with clinical depression, and community-dwelling adults. Journal of pain and symptom management, 25, 4, 307-318.

Baldwin, M. and Courneya, K. (1997). Exercise and self-esteem in breast cancer survivors: An application of the exercise and self-esteem model. Journal of Sport and Exercise Psychology, 19, 347-358.

Bandura, A. (2001) Social cognitive theory: an agentic perspective, Annual Review of Psychology, 52, 1-26.

Bower, J.; Ganz, P.; Desmond, K.; Rowland, J.; Meyerwitz, B.; Belin, T. (2000). Fatigue in breast cancer survivors: occurrence, correlates, and impact on quality of life. Journal of Clinical Oncology, 18, 4, 743.

Brown, Cash, Mikulka (1990). Multidimensional Body Self-Relations Questionnaire.

Cadmus, L.; Salovey, P.; Yu, H.; Chung, G.; Kasl, S.; Irwin, M. (February 2009). Exercise and quality of life during and after breast cancer: results of two randomized controlled trials. Psycho-Oncology, 18, 343-352. 
Carpenter, J.; Brockopp, D.; Andrykowski, M. (1999). Self-transformation as a factor in the self-esteem and well-being of breast cancer survivors. Journal of Advanced Nursing, 29, 6, 1402-1411.

Cohen, S. and Williamson, G. Perceived Stress in a probability sample of the United States. Spacapan, S. and Oskamp, S. (Eds.) The Social Psychology of Health. Newbury Park, CA: Sage, 1988.

Courneya, K.; Blanchard, C.; Laing, D. (February 2001). Exercise adherence in breast cancer survivors training for a dragon boat competition: a preliminary investigation. Psycho-Oncology, 10, 440-452.

Culos-Reed, S.; Shields, C.; Brawley, L. (2005). Breast cancer survivors involved in vigorous team physical activity: psychosocial correlates of maintenance participation. Psycho-Oncology, 14, 594-605.

Curbow, B. and Somerfield, M. (1991). Use of the Rosenberg Esteem Scale with adult cancer patients. Journal of Psychosocial Oncology, 9(2), 113-131.

Damush, T.; Perkins, A.; Miller, K. (2005). The implementation of an oncologist referred, exercise self-management program for older breast cancer survivors. Psycho-Oncology, 12, 10, 884-890.

Degrogatis, L.; Morrow, G.; Fetting, J.; Penman, D.; Piasetsky, S.; Schmale, A.; Henrichs, M.; Carnicke, C. (1983). The prevalence of psychiatric disorders among cancer patients. Journal of the American Medical Association, 246(6), 751-757. 
Durak, E.; Harris, J.; Ceriale, S. (November 2001). The effects of exercise on quality of life improvements in cancer survivors; the results of a national survey. Journal of Exercise Physiology Online, 4, 1-4.

Ebel, R.; Aldana, S.; Bloswick, D.; Lyon, J. (2003). A pilot study evaluating a peer led and professional led physical activity intervention with blue-collar employees. Work: A Journal of Prevention, Assessment, and Rehabilitation, 21, 3, 199-210.

Farrel, S.; Braun, L.; Barlow, C.; (2002). The relation of body mass index, cardiorepsiratory fitness, and all-cause mortality in women. Obesity Resource, 10, 417-423.

Frederick, C. and Ryan, R. (1993). Differences in motivation for sport and exercise and their relations with participation and mental health. Journal of Sport Behavior, 16.

Ganz, P.; Kwan, L.; Stanton, A. (2004). Quality of Life at the end of primary treatment of breast cancer diagnosis: influence of demographic, prognostic, and lifestyle factors. Journal of the National Cancer Institute, 96(5), 376-387.

Gay, C.; Kee, K.; Lee, S. (1992). General Sleep Disturbance Scale. NIH Public Access.

Hadd, V.; Sabiston, C.; McDonough, M.; Crocker, P. (2010) Sources of stress for breast cancer survivors involved in dragon boating: examining associations with treatment characteristics and self-esteem. Journal of Women's Health, 19(7), 1345-1353. 
Hopwood, P. and Maguire G. (1988). Body image problems in cancer patients. British Journal of Psychiatry, 153(2), 47-50.

Hosaka, T.; Aoki, T. (1996) Depression Among Cancer Patients. Psychiatry and Clinical Neurosciences, 50, 6, 309-312.

Kendall, A.; Mahue-Giangreco, M.; Carpenter, C.; Ganz, P.; Berstein, L. (2005). Influence of exercise on quality of life in long-term breast cancer survivors. Quality of Life Research, 14, 361-371.

Klem, M.; Wing, R.; McGuire, M. (1997). A descriptive study of individuals successful at long-term maintenance of substantial weight loss. American Journal of Clinical Nutrition, 66, 239-246.

Kornblith, A.;Powell, M.; Regan, M.; Bennett, S.; Krasner, C.; Moy, B.; Younger, J.; Goodman, A.; Berkowitz, R.; Winer, E. (2007). Long-term psychosocial adjustment of older vs. younger survivors of breast and endometrial cancer. Psycho-Oncology, 6, 895-903.

Lengacher, C.; Johnson-Mallard, V.; Post-White, J.; Moscoso, M.; Jacobsen, P.; Klein, T.; Widen, R.; Fitzgerald, S.; Shelton, M.; Barta, M.; Goodman, M.; Cox, C. (2009). Randomized controlled trial of mindfulness-based stress reduction (MBSR) for survivors of breast cancer. Psycho-Oncology, 18, $1261-1272$.

Luszczynska, A. \& Schwarzer, R. (2005). Social Cognitive Theory. In Conner, M. \& Norman, P (Eds.). Predicting Health Behavior, $2^{\text {nd }}$ Edition (127-161). New York: Open University Press. 
Maddux, J.E. (1995) Self-efficacy, Adaptation, and Adjustment: Theory, Research, and Application. New York: Plenum.

Marcus B.; Selby V.; Niaura R.; Rossi J. (1992). Self-efficacy and the stages of exercise behavior change. Research Quarterly of Exercise and Sport, 63, $60-66$.

Maryam, A.; Fazollah, A.; Eesa, M.; Ebrahim, H.; Abbas, V. (2010). The effect of designed exercise programme on quality of life in women with breast cancer receiving chemotherapy. Nordic College of Caring Science, 24, 251-258.

Matthews, C.; Chen, K.; Freedson, P.; Buchowshi, M.; Beech, B.; Pate, R.; Troiano, R. (2008). Amount of time spent in sedentary behaviors in the United States, 2003-2004. American Journal of Epidemiology, 167, 7, 875881.

McCorkle, R.; Quint-Benoliel, J. (1983). Symptom distress, current concerns and mood disturbance after diagnosis of life-threatening disease. Social Science \& Medicine, $7,17,431-438$.

McDonough, M.; Sabiston, C.; Crocker, P. (March 2007). An interpretative phenomenological examination of psychosocial changes among breast cancer survivors in their first season of dragon boating. Journal of Applied Sport Psychology, 20, 425-440. 
McKelvie, S.;Lemieux, P.: Stout, D. (2003). Extraversion and neuroticism in contact athletes, no contact athletes and non-athletes: A research note. Athletic Insight, the Online Journal of Sport Psychology, 5, 3.

McKenzie, D. (August 1998). Abreast in a Boat- race against breast cancer. Canadian Medical Association Journal, 159, 376-378.

McKenzie, D.; Kalda, A. (2003). Effect of upper extremity exercise on secondary lymphedema in breast cancer patients: A pilot study. Journal of Clinical Oncology, 21(3), 463-466.

McNair, D., Lorr, M., \& Droppleman, L. (1971). Profile of Mood States. San Diego: Education and Industrial Testing Service.

McNeely, M.; Campbell, K.; Rowe, B; Klassen T.; Mackey, J.; Courneya, K. (July 2006). Effects of exercise on breast cancer patients and surivors: a systematic review and meta-analysis. Canadian Medical Association Journal, 175(1), 34-41.

Mitchell, T.; Nielsen, E. (2001). Living Life to the Limits: Dragon Boaters. Canadian Woman Studies, 21, 3.

Mitchell, T.; Yakiwchuk, C.; Griffin, K.; Gray, R.; Fitch, M. (2007). Survivor dragon boating; a vehicle to reclaim and enhance life after treatment for breast cancer. Health Care for Women International, 28,122-140.

National Institute of Mental Health (2005). http://nimh.nih.gov. Retrieved from the world wide web 29 November 2010.

Otte, J.; Carpenter, J.; Russell, K.; Bigatti, S.; Champion, V. (March 2010). Prevalence, severity, and correlates of sleep-wake disturbances in long- 
term breast cancer survivors. Journal of Pain and Symptom Management, 39(3), 535-547.

Paffenbarger R.; Wing A.; Hyde R. (1978). Paffenbarger physical activity questionnaire. pp. S83-S88.

Parry, D. (2009). The contributors of dragon boat racing to women's health and breast cancer survivorship. Qualitative Health Research, 188(2), 222-233.

Parry, D. (2006). "There is life after breast cancer": Nine vignettes exploring dragon boat racing for breast cancer survivors. Leisure Sciences, 29, 5369.

Pinto, B.; Maruyama, N.; Clark, M.; Cruess, D.; Park, E.; Roberts, M. (2002). Motivation to modify lifestyle risk behaviors in women treated for breast cancer. Mayo Clinic Proceedings, 77, 122-129.

Polinsky, M. (1994). Functional status of long-term breast cancer survivors: demonstrating chronicity. Health and Social Work, 19.

Prochaska, J.J., Rodgers, M.W., and Sallis, J.F. (2002). Association of parent and peer support with adolescent physical activity. Research Quarterly for Exercise and Sport, 73, 206-210.

Radloff, L.S. (1977) 'The CES-D scale: A self report depression scale for research in the general population'. Applied Psychological Measurement, $1,385-401$.

Rosenberg, Morris. 1989. Society and the Adolescent Self-Image. Revised edition. Middletown, CT: Wesleyan University Press. 
Sabiston, C.; McDonough, M.; Crocker, P. (2007). Psychosocial Experiences of breast cancer survivors involved in a dragon boat program; exploring links to positive psychological growth. Journal of Sport \& Exercise Psychology, 29, 419-438.

Sallis, J.F.; Pinski, R.B.; Grossman, R.M.; Patterson, T.L.; Nader, P.R. (1988). he development of self-efficacy scales for health-related diet and exercise behaviors. Health Education Research, 3, 283-292.

Schover, L.; Yetman, R.; Tuason, L.; Meisler, E.; Esseltyn, C.; Hermann, R.;

Grundfest-Broniatoski, S.; Dowden, R. (January 1995). Cancer, 75(1), 54-64.

Stewart, (1988). General Health Survey of the Medical Outcomes Study. United States Dragon Boat Federation. (26 October 2010). http://www.usdbf.com. Retrieved from the world wide web on 29 November 2010.

Unruh, A. and Elvin, N. (June 2004). In the eye of the dragon: Women's experience of breast cancer and the occupation of dragon boat racing. Canadian Journal of Occupational Therapy, 71(3), 138-149.

Wiggins, M. and Simonavice, E. (2009). Quality of life benefits in cancer survivorship with supervised exercise. Psychological Reports, 104, 421-424. 